\title{
Hypermnesia for high-imagery words: The effects of interpolated tasks
}

\author{
GERALDINE A. SHAW \\ Georgetown College, Georgetown, Kentucky \\ and \\ D. A. BEKERIAN \\ MRC Applied Psychology Unit, Cambridge, England
}

\begin{abstract}
The purpose of this study was to determine whether hypermnesia (improved net recall over time) can be differentially affected by manipulating the nature of tasks performed during the intervals between successive recall trials. In Experiment 1, all subjects were asked to imaginally encode separate words and were tested three times for recall. The control group (no interpolated task) produced the hypermnesia effect. Both groups performing interpolated tasks showed significantly lower recall. A second experiment was conducted in order to replicate these results and to examine the effects of intertest rehearsal on hypermnesia. In Experiment 2, subjects were asked to encode pairs of words using interactive-imagery instructions. Six different interpolated task conditions were employed, varying in the degree to which subsystems of working memory were used. Groups performing imaginal interpolated tasks showed no hypermnesia, whereas those performing nonimaginal tasks did. These findings suggest that access to working memory (see Baddeley, 1986) is not necessary for hypermnesia.
\end{abstract}

Ballard, in 1913, reported an effect in which the net recall of poetry seemed to increase over time, despite the fact that no subsequent learning or rehearsal trials had been given during the retention interval. He described this phenomenon as reminiscence. Subsequent attempts at replicating Ballard's findings provided only mixed results (e.g., Buxton, 1943), and investigations of the effect ceased for several years. Buxton's (1943) criticisms of the research procedures used by various experimenters centered around the idea that subjects might be engaging in covert rehearsal or review during the retention intervals and that this might account for the varied results in reminiscence research. He suggested that control of rehearsal during the retention interval might be accomplished either by occupying subject's minds during retention with such tasks as prose reading, problem solving, and so forth, or by having subjects recall the items in repeated recall trials, thereby ensuring rehearsal during the retention interval.

The past decade has brought an accumulation of evidence that must be taken as indicating a strongly renewed

Both authors contributed equally to this research. Experiment 1 was conducted while G. A. Shaw was a Visiting Scientist at the Medical Research Council, Applied Psychology Unit. She wishes to express her gratitude to the director, Alan Baddeley, and staff of the Unit for their help with this work. The authors also acknowledge the useful comments of D. Payne. Experiment 1, in a similar form, was presented to the Meeting of the American Psychological Association, August, 1986, in Washington, DC. Correspondence should be addressed to D. A. Bekerian, MRC Applied Psychology Unit, 15 Chaucer Road, Cambridge, CB2 2EF, England. interest in the phenomenon (see Erdelyi, 1984). In parallel, the concept of hypermnesia has been more precisely defined. Payne (1987), in his extensive review, noted that reminiscence refers to the recall of previously unrecalled items and that hypermnesia is used in referring to "improvements in net recall levels associated with increasing retention intervals" (p. 9). Although there has been considerable theoretical development, little of the work has systematically considered Buxton's (1943) early concern about the importance of what subjects do during retention intervals (e.g., the intervals between successive recall attempts). To be sure, all theories of hypermnesia would argue that anything that might affect item accessibility (e.g., retrievability) will influence hypermnesia. Thus, an interpolated activity may, or may not, affect hypermnesia to the extent that item accessibility is influenced. However, the exact relationship between item accessibility and interpolated activity is only vaguely alluded to in theoretical statements.

We decided to explore this relationship by varying the nature of the interpolated task performed between successive recall trials. It has already been shown that similarity of interpolated tasks will affect item accessibility (e.g., Bekerian, 1986). In the present study, all subjects were asked to encode to-be-remembered (TBR) items (highimagery words) by forming an image of the stated object. One group was required to perform an identical, interpolated task (e.g., to form separate, single images); another group performed an interactive-imagery task. Effects of interpolated tasks were examined for recall, cumulative recall, forgetting, and reminiscence. 
It could be argued that an interpolated task using imagery may decrease item accessibility by rendering the TBR items less discriminable in memory. That is, cues generated or used on subsequent recall trials may become less distinct and, consequently, make retrieval more difficult, when the interpolated material is processed in a similar fashion (e.g., Morton, Hammersley, \& Bekerian, 1985; Norman \& Bobrow, 1979). Following this argument, it might be anticipated that performing an interpolated task that is identical to the encoding task will reduce item accessibility more than will performing a similar, but nonidentical, interpolated task, although the latter may also reduce accessibility. As such, we might expect the effects of an interactive-imagery task on accessibility of TBR items to be less severe than those of a separate imagery task, in spite of the fact that the former results in high recall levels in general (e.g., Bower, 1970).

To ensure that hypermnesia could be obtained, every effort was made to replicate the conditions that have been shown to be important in eliciting hypermnesia: use of an imagery task in the TBR items (Erdelyi, Finkelstein, Herrell, Miller, \& Thomas, 1976; Payne, 1986), use of repeated recall trials (Roediger \& Payne, 1982), encouragement of guessing during recall (Belmore, 1981), provision of sufficient time for recall (Roediger \& Thorpe, 1978) and, specifically, more than 5 sec per TBR item (Payne, 1987), and allowing subjects to think about the words (Erdelyi \& Becker, 1974) as a control procedure.

\section{EXPERIMENT 1}

\section{Method}

Subjects. Fifty subjects were recruited from members of the subject panel at the Applied Psychology Unit. All individuals were paid for their participation. The subjects were tested in groups of 16 or 17. The control group consisted of 16 subjects; each of the two experimental groups was made up of 17 subjects. The age and sex distributions of the three groups were comparable. The mean age of subjects was 44.67 years.

Design. A 3 (instructions: separate imagery, interactive imagery, and control) $\times 3$ (recall trials: 1,2 , and 3 ) mixed-factor design was used, with instructions being a between-group factor and trials being a repeated measure.

Materials. The study list was composed of 30 pairs of one- and two-syllable concrete nouns. ${ }^{1}$ Pairs of words were presented on slides, one above the other. All words were high in printed frequency (A or AA), according to Thorndike and Lorge's (1944) word-frequency norms, and had a mean imagery rating of 6.51 (Paivio, Yuille, \& Madigan, 1968). Pairing of words was done randomly, with the restriction that no clearly evident associations existed between words making up cach pair. An additional 48 words were selected to serve as materials for the two interpolated tasks. These words were concrete nouns with a mean imagery rating of 6.0 (Paivio et al., 1968) and had not been seen previously in the study trial. The 48 words then were randomly paired, with no associations between words making up each pair. Twelve pairs of words served as stimuli for the first intertest interval, and the remaining 12 pairs served as stimuli for the second intertest interval, with order of appearance counterbalanced for subjects within each condition. The 12 pairs of words for each intertest interval were presented in booklets with one pair per page.

Procedures. The subjects, seated in front of a blank screen, were given written instructions indicating that they would be shown pairs of words, one word printed on top of the other. Half of the subjects in each group were instructed to learn each top word and to ignore the bottom word; the other half were asked to learn the bottom word and to ignore the top member of the pair. The subjects were told that they should form a visual image of each word to be learned, as it would help them to recall the word later. They were then shown 30 slides containing the word pairs, at a rate of $6 \mathrm{sec}$ each. Following this, the subjects were given verbal instructions to recall as many as possible of the words they had just imaged. Every subject was then given a sheet containing 30 numbered lines and told to fill in a word for each line, even if they felt they were guessing (see Erdelyi \& Becker, 1974), during a 6-min period. A warning was given to subjects when there were only 2 min left in the recall trial. This constituted the first recall trial.

After the first recall trial, an intertest interval of 6 min was introduced. For the control subjects, the instructions were to sit quietly for the duration of the interval and think about the words on the slides for which they had formed images. The subjects receiving separate-imagery instructions (the separate group) were told that each of them would be given a booklet, with one pair of words per page. For each word pair, they were to form separate images of the objects depicted by each word, so that the images would appear on separate ends of an imaginary wall. The subjects receiving interactive-imagery instructions (the interactive group) were told that each of them would be given a booklet with one word pair appearing on each page. For each word pair, they were to form an image, so that the objects depicted by the words were clearly interacting with one another in some way. Examples of both types of imagery task were given. The subjects in the separate and interactive groups were given $30 \mathrm{sec}$ in which to form images of each word pair before they were instructed to turn to the next page. The entire intertest interval lasted about $6 \mathrm{~min}$. After this interval, booklets were collected and all subjects were given a new recall sheet. All subjects were given the same recall instructions and procedures as had been used in the first recall trial.

Following the second recall trial, the subjects were given intertestinterval instructions according to group. The separate group was given another booklet containing a new set of 12 word pairs, as was the interactive group. The second intertest interval lasted $6 \mathrm{~min}$, after which the same procedures for recall were followed. At the conclusion of the third recall trial, the subjects were given a final recall sheet. They were asked to recall as many as possible of the words on the slides that they had been told to ignore (e.g., those words that we incidentally paired with the to-be-learned words). This was done in order to determine whether or not the subjects had followed instructions to ignore one member of each word pair and to assess whether or not there was any incidental learning of the to-be-ignored items. For the final task, each subject in the separate and interactive conditions was given a sheet of paper containing one of each of the 24 word pairs presented during intertest intervals. The subject was asked to write, in the blank opposite each word, the word he/she thought had been paired with it in the booklet. This was done to ensure that the subjects had understood and successfully performed the imagery instructions given to them during the intertest intervals.

\section{Results}

An analysis of variance (ANOVA) was conducted on mean number of correct words recalled (net recall) as a function of instructions and trials, with instructions being a between-group factor and trials being a repeated measure. All analyses reported are significant at $p<.05$, or less. Means for recall over trials are presented in Table 1 as a function of group.

There was no main effect of instruction on net recall $(F=1.53)$. The effect of trials proved to be significant 
Table 1

Experiment 1: Mean Free-Net Recall Performance on Three Trials

\begin{tabular}{|c|c|c|c|c|c|}
\hline Trial & $\%$ Items & $\begin{array}{l}\text { Number } \\
\text { of Words }\end{array}$ & $\begin{array}{c}\text { Cumulative } \\
\text { Words }\end{array}$ & $p(F / R)$ & $p(R / F)$ \\
\hline \multicolumn{6}{|c|}{ Interactive Condition } \\
\hline 1 & $85^{a}$ & 16.72 & & & \\
\hline 2 & $3^{b}$ & 14.88 & 17.23 & .17 & .08 \\
\hline 3 & $4^{c}$ & 14.88 & 17.88 & .16 & .09 \\
\hline \multicolumn{6}{|c|}{ Separate Condition } \\
\hline 1 & $57^{a}$ & 16.06 & & & \\
\hline 2 & $21^{b}$ & 13.81 & 17.88 & .25 & .14 \\
\hline 3 & $5^{c}$ & 14.13 & 18.56 & .20 & .10 \\
\hline \multicolumn{6}{|c|}{ Control Condition } \\
\hline 1 & $80^{\mathrm{a}}$ & 16.88 & & & \\
\hline 2 & $10^{\mathrm{b}}$ & 16.75 & 18.63 & .11 & .10 \\
\hline 3 & $9^{c}$ & 18.18 & 20.25 & .09 & .16 \\
\hline
\end{tabular}

${ }^{\mathrm{a}}$ Percentage of Trial 1 items recalled across all trials. ${ }^{\mathrm{b}}$ Percentage of Trial 2 items introduced in Recall $2 . \quad$ 'Percentage of Trial 3 items introduced in Recall 3.

$[F(2,92)=3.79, M S=4.49]$. However, the instruction $\times$ trials interaction was also significant $[F(4,92)=2.88$, $M S=4.47]$. The only significant effect of instruction was at Trial $3[F(2,60)=3.36, M S=22.92]$, with the control group showing significantly higher net recall than either the separate or interactive groups ( 18.18 vs. 14.13 and 14.88 , respectively). This suggests that the separate and interactive groups suffered some interference from the interpolated task.

To assess hypermnesia, planned comparisons were conducted on mean net recall scores in Trials 1 and 3 for each instruction group. The control group showed a significant improvement in net recall from Trial 1 to Trial 3 $[F(1,15)=7.83, M S=1.76]$. In contrast, significant impairment in net recall between Trial 1 and Trial 3 was observed for the interactive and separate groups $[F(1,16)=$ $8.84, M S=1.2$, and $F(1,15)=11.71, M S=2.56$, respectively].

Also of interest were the patterns of net recall between Trials 2 and 3 . The only significant effect was in the control group, with net recall on Trial 2 significantly poorer than on Trial $3[F(1,15)=13.78, M S=1.2]$.

ANOVAs were conducted on numbers of unique words (cumulative recall) recalled across trials (see Table 1). The only significant effect was of trials $[F(2,92)=75.65$, $M S=1.10]$, with significant increases between Trials 1 and 2 occurring only in the separate and control groups $[F(1,15)=42.76, M S=.61 ; F(1,15)=21.00, M S=$ 1.17]. All groups, however, showed significant increases between Trials 2 and 3 [separate, $F(1,15)=5.25, M S=$ .25 ; interactive, $F(1,16)=8.99, M S=.40$; control, $F(1,15)=15.18, M S=1.39$ ]

Also included in Table 1 are percentages of items repeated across all three trials and percentages of items original to Trial 2 and Trial 3. For the group showing hypermnesia (control), the percentages of items introduced across early and late trials are equivalent.
ANOVAs were then conducted on mean conditional probabilities measuring forgetting and reminiscence (see Table 1). Belmore's (1981) procedure of conditionalizing performance against Trial 1 was followed.

The only effect to reach significance was that of measures, with more forgetting being demonstrated $[F(1,46)=$ $1.09, M S=.022]$. It should be noted that mean probability levels for reminiscence did exceed that for forgetting in the control group (.26 vs. .20 ), with this difference emerging on Trial 3. However, neither the instruction $x$ measure interaction nor the instruction $x$ trial $\times$ measure interaction reached significance $[F \mathrm{~s}(2,46)=2.62$ and $F<1$, respectively].

Analyses performed on mean number of correct recall and matching for incidental words in the study list (i.e., those ignored) failed to show any significant differences. To assess performance on the interpolated tasks, an analysis of correct pairings of interpolated word pairs showed that the interactive group was significantly better at pairing words than was the separate group, with the respective means being 15.94 and $7.44[F(1,34)=18.29$, $M S=32.93]$. This indicates that groups had followed the particular instructions for imaging given during the intertest intervals.

\section{Discussion}

We have illustrated that interpolated activity can influence item accessibility. Imaginal interpolated tasks eliminated hypermnesia relative to a control. Thus, factors that have previously been shown to elicit hypermnesia were not sufficient to override the inhibiting effects of interpolated tasks.

Other features of the data warrant consideration. First, improvement in net recall across trials in the group showing hypermnesia occurred late, rather than early, in the testing sessions. This finding replicates those reported by Belmore (1981, Experiment 1), who also showed nonsignificant differences between the first two recall attempts. Furthermore, an equal percentage of items was introduced between early and late recall attempts. In combination, and similar to other comparisons made by Payne (1986), such results do not support a prediction of the recall level hypothesis that "the magnitude of the improvements in recall levels ... decreases monotonically across successive pairs of tests" (Payne, 1987, p. 16).

Another facet of the data needing explanation is the relationship between cumulative recall and hypermnesia. According to Payne (1987), hypermnesia will depend not only on increasing the accessibility of items not previously recalled, but also on increasing the probability that previously retrieved items will be recovered in future trials. Following this line of reasoning, hypermnesia should be associated with increases in intertest reminiscence and with decreases in intertest forgetting. This predicted pattern was observed in the group showing hypermnesia. Furthermore, the separate and interactive groups, which failed to show hypermnesia, showed decreases in inter- 
test forgetting without simultaneous increases in recovery. Both of these patterns accord with Payne (1986).

However, an important qualification is necessary. The predicted patterns in changes of reminiscence and forgetting were not significant across trials, although significant increases in cumulative recall were noted. These findings are consistent with those reported by Belmore (1981), but are in contrast to those reported by Payne (1986), who analyzed mean number of items recovered and forgotten across trials. It should be noted that in Payne's analysis, number of items forgotten or recovered were not conditionalized on the subjects' initial recall level. This difference between conditional probabilities and mean number of items may account for the discrepancies between our findings and those of Payne (1986).

The nature of the interpolated activity would thus seem to be one of the factors influencing item accessibility, if item accessibility is associated with hypermnesia (Payne, 1986). However, the basis of this influence remains unspecified from these data. In fact, there are at least three explanations of why interpolated activity might decrease item accessibility and prevent hypermnesia.

The simplest explanation is that the introduction of any novel stimuli during an interpolated interval will reduce TBR item accessibility. Given that both interpolated activities reported here required imaginal processing, the unique effects of imaginal processing cannot be ascertained. This explanation can be examined by including interpolated activities of a different sort (e.g., reading). However, this explanation still begs the question as to why any interpolated or novel stimuli decrease item accessibility. Furthermore, findings such as those reported by Shaw $(1986,1987)$, who showed that subjects highly involved in creativity tasks during intertest intervals produced hypermnesia for high-imagery words, are also difficult to explain by this account.

A more specific explanation for why interpolated activity might influence item accessibility is that an interpolated activity prevents items from being maintained in working memory (see Baddeley, 1986). It could be argued that entrance into working memory (e.g., intertest rehearsal) enables retrieval cues to be enhanced, refreshed, reinstated, or elaborated, thereby increasing the likelihood of item accessibility. When access to working memory is denied, such benefits cannot accrue. This explanation would suggest that any interpolated activity requiring working memory capacity will prevent hypermnesia if the crucial subsystem is used. That is, one can assume that high-imagery words that have been processed imaginally (as used here) will be rehearsed in both the visual shortterm buffer (i.e., VSSP) and the verbal short-term buffer of working memory (Baddeley, 1986). If different interpolated activities can be used to systematically remove the contribution of a subsystem (or buffer), we might be better able to determine the locus of the effects of intertest rehearsal.

For example, if a star-tracing task were performed during the interpolated intervals, VSSP rehearsal should be prevented (e.g., Baddeley, Grant, Wight, \& Thomson,
1975). If VSSP rehearsal is important, no hypermnesia should be observed. This prediction will hold only if it is assumed that the use of the same processing system is crucial, rather than the nature of the materials being processed (e.g., words processed at both encoding and intertest intervals) or the interaction between the materials and the processing system (e.g., imaging highly imageable words both at encoding and in interpolated interval).

A star-tracing task is an appropriate task to assess the unique importance of the processing systems, because it requires the sensorimotor and spatial aspects of VSSP but does not involve the semantic processing used with verbal material. What is also needed is a task requiring semantic processing and VSSP processing, but one in which pictorial images are not required to be generated. A task of reading prose during the interpolated interval fulfills these requirements. Because reading would occupy both subsystems of working memory, we would expect no hypermnesia.

Of course, there is always the possibility that workingmemory rehearsal is not necessary in order to increase item accessibility. For example, anything that might increase the discriminability of descriptions (e.g., retrieval cues) needed to access TBR items should increase item accessibility (see Morton, et al., 1985; Norman \& Bobrow, 1978). Thus, an interpolated activity may, in fact, increase item accessibility if it requires sufficiently different processing of sufficiently different materials. This explanation suggests that the interpolated activities used in Experiment 1 overtaxed descriptive cues, such that the cues/descriptions necessary to access TBR items were no longer distinct from those associated with the interpolated materials. According to this view, only tasks requiring the imaginal processing of highly imageable words should inhibit hypermnesia.

A second experiment was designed to examine some of these predictions by including as interpolated activities a star-tracing task and a prose-reading task, in addition to the two imaging tasks. One prediction is that workingmemory rehearsal is necessary to increase item accessibility and, hence, necessary for hypermnesia to occur. If this were true, then we would expect that tasks that occupy working memory should inhibit hypermnesia. Thus, groups performing any interpolated task will not show hypermnesia. An alternative prediction is that decreases in the discriminability of retrieval cues for the TBR items reduce item accessibility and, consequently, inhibit hypermnesia. Thus, only the interpolated activities that involve similar processing of similar materials should impair hypermnesia. This means that only those groups performing imaging tasks will fail to show hypermnesia.

\section{EXPERIMENT 2}

Experiment 2 also attempted to address a few uncertainties in the interpretation of the findings of Experiment 1 . The first is the finding that groups receiving interpolated tasks demonstrated two separate phenomena: impairment relative to a control (between subjects, inter- 
ference) and significant decrease in performance relative to initial recall (within group, interference). Thus, not only did these groups fail to show hypermnesia, they also demonstrated interference, both within and between groups. A possible criticism is that we are attempting to make inferences about hypermnesia from groups that actually showed interference. It should be remembered that an interpolated activity could have had one of three possible effects on recall: one in which there is an increase in overall recall (e.g., hypermnesia), one in which there is no change in overall recall (e.g., no hypermnesia), and one in which there is a decrease in overall recall (e.g., interference). Ideally, the appropriate comparison would contrast groups showing hypermnesia with groups not showing hypermnesia-a comparison that cannot be made on the basis of the data from Experiment 1. Accordingly, it was decided to use an interactive task to ensure more robust memories at encoding than those produced by the separate-imaging task (see Bower, 1970).

Another critical point concerns a potential confound in the control group. As argued by Payne (1986), the hypermnesia observed in that group may have been the result of two components: intertest retrieval (rehearsal) and test retrieval. However, the act of retrieving an item at test may serve to increase item accessibility by forming new memories (e.g., Morton et al., 1985), and this facilitation may be more important than that accrued from intertest rehearsal. To isolate the importance of intertest rehearsal, we included an additional control group in which subjects were given no intertest intervals and, consequently, no opportunity for intertest rehearsal. Should these subjects show hypermnesia, it would have to be due to increases in item accessibility resulting from test retrieval only. A comparison of this group with a control group receiving intertest intervals (e.g., think of words during the interval) should allow us to examine further the importance of intertest rehearsal on item accessibility.

\footnotetext{
Method

Subjects. A total of 120 Georgetown College undergraduates, all enrolled in introductory psychology courses, participated as subjects in partial fulfillment of those courses. Assignment to each of six equal, independent groups was achieved by asking the subjects to sign up for desired testing period times. The balance of males and females was comparable in all groups.

Design. A 6 (instructions: interactive imagery, separate imagery, star tracing, prose reading, control, and no interval) $\times 3$ (recall trials: 1, 2, and 3) mixed-factor design was used, with instruction being a between-group factor and trials being a repeated measure.

Materials. The study list of 30 pairs of words on slides was the same as those used in Experiment 1. The sheets used for the three recall trials contained 60 numbered lines, instead of the 30 used in Experiment 1, as subjects were asked to recall all 60 words for this experiment. The interpolated tasks using the interactive- and separate-imagery instructions contained the same 48 words in the same presentation mode as that used in Experiment 1. The matching task that was employed in Experiment 1 was also used here. The materials for the control and no-interval groups were the same as those used in Experiment 1. For the star-tracing interpolated task, sheets of paper containing two concentric, six-pointed stars were used. The larger star was approximately $8 \mathrm{in}$. high, and the smaller star was drawn 0.25 in. inside the larger. Instructions printed on
}

each sheet were, "Please draw 3 concentric stars between the lines of the two stars given on this page. Please work slowly and carefully so that all lines will be completely parallel." For the reading interpolated task, a copy of the article "Are Criminals Made or Born?"' by R. J. Herrnstein and J. Q. Wilson (published in the New York Times Magazine, August 4, 1985, pp. 35-38) was given to each student. A set of 12 multiple-choice questions was constructed to ensure each subject's memory of the article.

Procedures. The main difference between Experiment 1 and Experiment 2 is that, in the former, the subjects used separate imagery to encode the TBR words, whereas in the present experiment, interactive-imagery instructions were used for these words.

The order of presentation for all groups was (1) the initial study period with interactive-imagery instructions, (2) Recall Test 1 , (3) Intertest Interval 1, (4) Recall Test 2, (5) Intertest Interval 2, and (6) Recall Test 3. The exception to this procedure was that the intertest intervals were omitted for the no-interval groups. Finally, the interactive-imagery, separate-imagery, and prose-reading groups were tested to ensure that they had completed the interpolated tasks assigned to each group. For the star-tracing group, the completed stars were taken as evidence of correct participation.

The study procedures employed for all groups in Experiment 2 were identical to those used in Experiment 1, except that the subjects were given written instructions for interactive imagery asking them to form an image of the two objects clearly interacting with one another. ${ }^{2}$ The procedures for the interpolated tasks of separate and interactive imagery were identical to those in Experiment 1 . The procedure for the control group was identical to that in Experiment 1. For the no-interval group, three consecutive recall trials were given with no time between trials. For the star-tracing group, the subjects were given three sheets of paper containing stars for each of the intertest intervals and were told to ask for more if these were completed during the 6-min intervals. However, no subject needed additional star-tracing sheets. These sheets were collected after each interval. For the prose-reading interpolated task, each subject was handed the above-described article to read during the two 6-min intervals and was asked to reread the article if he/she finished before the allotted time had passed. These articles were collected after each interval.

\section{Results}

An ANOVA was conducted on mean net recall using a 6 (instruction group) $\times 3$ (net recall trial) mixed design. Table 2 provides mean numbers of recall as a function of group and trial.

An analysis of the main effect of instruction group failed to reach significance, thereby replicating Experiment 1 . It should be noted that all groups were equal in recall on Trial 1. The main effect of trials was significant $[F(5,114)=22.95, M S=6.48]$, as was the instruction $\times$ trial interaction $[F(10,228)=2.23, M S=6.48]$. With the exception of the interactive group, all groups showed significant differences in net recall across trials [all $F \mathrm{~s}(2,38)>4.13]$.

To assess hypermnesia, weighted comparisons were conducted. There were no significant differences between Trials 1 and 3 in either the interactive group or the separate group, indicating no hypermnesia. For all other groups, there were significant improvements in levels of net recall between Trials 1 and 3, indicating hypermnesia [all $F \mathrm{~s}(1,19)>4.75]$.

Analyses were also conducted on differences in net recall between Trials 1 and 2 and between Trials 2 and 3 . There were no significant differences between Trials 
Table 2

Experiment 2: Mean Free-Net Recall Performance on Three Trials

\begin{tabular}{|c|c|c|c|c|c|}
\hline Trial & $\%$ Items & $\begin{array}{l}\text { Number } \\
\text { of Words }\end{array}$ & $\begin{array}{c}\text { Cumulative } \\
\text { Words }\end{array}$ & $p(F / R)$ & $p(R / F)$ \\
\hline \multicolumn{6}{|c|}{ Interactive Condition } \\
\hline 1 & $70^{a}$ & 26.50 & & & \\
\hline 2 & $7^{b}$ & 24.70 & 30.35 & .23 & .12 \\
\hline 3 & $9^{\mathfrak{c}}$ & 25.50 & 32.70 & .19 & .12 \\
\hline \multicolumn{6}{|c|}{ Separate Condition } \\
\hline 1 & $72^{a}$ & 26.30 & & & \\
\hline 2 & $13^{b}$ & 24.15 & 29.42 & .23 & .13 \\
\hline 3 & $14^{\mathrm{c}}$ & 26.65 & 33.05 & .19 & .15 \\
\hline \multicolumn{6}{|c|}{ Star-Tracing Condition } \\
\hline 1 & $64^{a}$ & 25.55 & & & \\
\hline 2 & $21^{b}$ & 24.40 & 30.45 & .19 & .12 \\
\hline 3 & $18^{\mathrm{c}}$ & 27.55 & 35.30 & .18 & .18 \\
\hline \multicolumn{6}{|c|}{ Reading Condition } \\
\hline 1 & $79^{a}$ & 26.75 & & & \\
\hline 2 & $11^{\mathrm{b}}$ & 26.85 & 29.80 & .17 & .12 \\
\hline 3 & $8^{c}$ & 28.75 & 32.05 & .13 & .15 \\
\hline \multicolumn{6}{|c|}{ No-Interval Condition } \\
\hline 1 & $79^{a}$ & 26.30 & & & \\
\hline 2 & $14^{b}$ & 27.00 & 30.00 & .11 & .09 \\
\hline 3 & $12^{c}$ & 29.20 & 33.45 & .11 & .16 \\
\hline \multicolumn{6}{|c|}{ Control Condition } \\
\hline 1 & $81^{a}$ & 26.55 & & & \\
\hline 2 & $13^{b}$ & 26.95 & 30.00 & .11 & .12 \\
\hline 3 & $12^{c}$ & 29.00 & 33.85 & .11 & .15 \\
\hline
\end{tabular}

${ }^{\mathrm{a}}$ Percentage of Trial 1 items recalled across all trials. ${ }^{\mathrm{b}}$ Percentage of Trial 2 items introduced in Recall $2 . \quad$ 'Percentage of Trial 3 items introduced in Recall 3.

1 and 2 in any of the groups showing hypermnesia. Thus, hypermnesia appeared only in later trials, as was found in Experiment 1.

Trials 1 and 2 in the interactive group were not significantly different. However, there was a significant decrease in recall between Trials 1 and 2 for the separate group $[F(1,19)=8.23, M S=6.43]$, although this decrease in recall was recovered in Trial 3 (Trial $1=$ Trial 3 performance). The inferiority of Trial 2 relative to both Trials 1 and 3 would appear to be responsible for the effect of trials in the separate group.

Finally, analyses were done on mean net recall scores within each instruction group for Trials 2 and 3 . All groups, with the exception of the interactive group, showed significant improvements in net recall [all $\left.F_{\mathrm{s}}(1,19)>5.54\right]$.

Analyses were conducted on mean cumulative recall scores (shown in Table 2). The only significant effect was that of trials, indicating that performance increased across repeated test trials $[F(1,114)=187.43, M S=3.03]$. Comparisons between Trial 1 and Trial 2 indicated significant increases in cumulative recall on Trial 2 for all instruction groups [all $F_{\mathrm{s}}(1,19)>26.77$ ]. Similarly, all groups showed significant increases in cumulative recall on Trial 3 [all $F \mathrm{~s}(1,19)>26.36$ ].

The basis of increases in cumulative recall can be seen through an inspection of mean conditional probabilities for reminiscence in Table $2[\mathrm{e} . \mathrm{g} ., p(R / F)]$. With one exception (interactive group), all groups showed numerical increases in reminiscence across Trials 2 and 3, although none of these increases were statistically significant. Interestingly, the magnitude of this increase was greatest for the groups showing hypermnesia (e.g., star-tracing, reading, control, and no-interval groups).

There were numerical decreases in intertest forgetting, with one exception (no-interval group), although these decreases were not statistically significant. However, the magnitude of decreases in intertest forgetting was greatest for the groups not showing hypermnesia (interactive and separate groups).

Also included in Table 2 are percentages of items originally introduced across early and late recall trials. As can be seen, there is little fluctuation across trials, replicating the findings presented in Experiment 1. Finally, performance on the interpolated tasks was examined. Mean cued recall for interpolated word pairs in the interactive and separate groups showed a significant difference [interactive $=17.00$, separate $=10.80 ; F(1,38)=14.19$, $M S=28.71$ ], replicating Experiment 1. For the reading group, the subjects correctly answered an average of 8.55 of 12 questions about the prose article (as opposed to an average of 6 correct for a group of 19 different psychology students who had not read the article), indicating that they had engaged in the interpolated task.

\section{Discussion}

We will first consider some of the more general findings that bear directly on Experiment 1 . One is that hypermnesia appeared late in the testing session (Trials 2-3) and not early (Trials 1-2), thereby replicating the effect observed in Experiment 1. Also, the proportion of items introduced in early and late trials was equivalent, as in Experiment 1. Thus, we have failed to find support for Payne's $(1986,1987)$ suggestion that increases in net recall are greater between early test trials. Again, we note that Belmore (1981) also failed to consistently show any increases in recall between early test trials.

We also did not obtain hypermnesia in the groups performing imaginal interpolated tasks (as in Experiment 1), although we were successful in avoiding between-group interference. This allows us to make more informative comparisons between groups showing hypermnesia.

Finally, we will discuss cumulative recall. Increases in cumulative recall were demonstrated by all groups, irrespective of whether or not hypermnesia was demonstrated. This replicates the findings in Experiment 1 and also supports other research noted by Belmore (1981). These findings seem to suggest that increases in reminiscence (i.e., the ability to retrieve previously unrecalled words) do not explain hypermnesia.

However, it should be remembered that hypermnesia may be obtained from different combinations of scores of reminiscence and forgetting. For example, there are at least four patterns reflecting the relationship between reminiscence and forgetting that would result in increases in cumulative recall: (1) reminiscence increases and forgetting decreases across trials, (2) reminiscence increases 
and forgetting stays the same across trials, (3) reminiscence stays constant and forgetting decreases across trials, or (4) reminiscence and forgetting remain constant across trials, but reminiscence was originally greater than forgetting in early trials and maintains its superiority. In Table 2 , it can be seen that, of the four groups showing hypermnesia, two illustrate Pattern 2 above (no-interval and control groups); the reading and star-tracing conditions show Pattern 1.

The importance of this point is that, although reminiscence must always exceed forgetting in order for hypermnesia to occur, the ways in which this relationship is achieved will vary across different conditions. In Experiment 2, different patterns were associated with differences in the nature of the interpolated activities. For the groups receiving no activities or activities that did not involve new materials, one pattern was observed in which forgetting was not affected. In contrast, the group receiving an interpolated task showed a pattern in which forgetting decreased. It could be that these subtle differences are indicative of qualitatively different operations involved in hypermnesia.

We advanced certain specific hypotheses concerning the influence intertest intervals might have on item accessibility. One was that an intertest interval provides an opportunity to rehearse in working memory, thereby increasing item accessibility. According to this line of reasoning, we argued that interpolated activities that disrupt rehearsal, by occupying working-memory capacity, should decrease item accessibility and should prevent hypermnesia. There was no support for this: Groups performing interpolated tasks that are known to disrupt differentially workingmemory subsystems, but were different in nature from the encoding task, still showed hypermnesia (e.g., startracing and reading groups). In contrast, only the groups performing interpolated activities similar in nature to the encoding task failed to show hypermnesia. This suggests that rehearsal during the intertest interval is not a necessary condition for hypermnesia, thereby addressing Buxton's (1943) original criticism.

Relevant to this is the additional finding that the magnitude of hypermnesia was not affected by intertest rehearsal (i.e., control hypermnesia was equivalent to nointerval hypermnesia). This provides further support for the suggestion that intertest rehearsal may not make a crucial contribution to hypermnesia. Additional evidence for this argument is found in Shaw and Bekerian's (1989) study, in which the intertests' use of TBR words in constructing verses was not correlated with hypermnesia.

A second explanation relies on the assumption that interpolated activities can affect the discriminability of cues used to retrieve TBR items. If we assume that memory traces will be formed for the interpolated activity and materials (e.g., Morton et al., 1985; Norman \& Bobrow, 1978) then similarities between the activity and the TBR items should reduce the discriminability of retrieval cues (or descriptions) generated at the time of test. This leads to the prediction that only imaginal activities, where the processing and the items were similar to those at encoding, should inhibit hypermnesia. This was the case.

A complementary explanation can be advanced to explain why nonimaginal tasks enabled hypermnesia. We can suggest that with repeated tests and intertest intervals, the distinctiveness of cues used to successfully access TBR items is heightened. Thus, subjects may not only have more distinctive descriptions (or cues) to access TBR items, but may also find it easier to avoid those cues or descriptions pertaining to interpolated materials. We would expect this to increase over trials, as was the case.

Of course, increased discriminability of cues or descriptions must be achievable through other means. Repeatedly recalling TBR items in succession without any intertest intervals could also be argued to help subjects maintain and monitor successful retrieval descriptions. Thus, even with no intertest rehearsal, more efficient cue generation might be expected.

\section{GENERAL DISCUSSION}

We have reported results in which hypermnesia has been influenced by an interpolated activity. On the basis of all the findings, it would seem that this influence (either positive or negative) is not the result of any extra rehearsals during the intertest intervals. Rather, it would seem to be related to whether the retrieval cues for to-beremembered items either are left intact or are further enhanced or degraded by performing an interpolated activity. Therefore, we might be able to define more precisely the concept of increased item accessibility (Payne, 1986) in terms of the maintenance or enhancement of discriminative and distinct retrieval cues or descriptions.

However, we still need to explain how item accessibility is realized. One suggestion is that subjects showing hypermnesia are more successful in forming retrieval descriptions that access the original memory for the encoded materials, rather than the more updated memory for items resulting from recall trials. Furthermore, we will assume that each event experienced by a subject leaves a corresponding memory or record to which are associated cues or descriptions that access the memory (see Morton et al., 1985; Norman \& Bobrow, 1979). We can assume that a general memory for the items at encoding is laid down specifying the distinctive features present at the time (e.g., type of processing, valence of stimulus materials, etc.; see Morton et al., 1985). During recall another updated version would be created, including the items recalled and any items that had been retrieved but not recalled (say, due to lowered confidence). Different retrieval descriptions would be formed for this memory, which would include some but not all of the retrieval cues associated with the original memory. If subjects are able to access original memory on successive trials, not only would previously recalled items be accessible, but also never-recalled items.

The emphasis on retrieval descriptions leads to questions about the cues that subjects attend to at the time of recall. 
Such questions would be concerned with how and why certain information is attended to and incorporated into retrieval descriptions. In this way, issues about the allocation of attention could have direct implications for discussions of item accessibility. We are not suggesting that the above explanation is the only one that can account for the data. However, the explanation at least provides a framework through which discussions of item accessibility, reminiscence, and forgetting might become more focused.

\section{REFERENCES}

Baddeley, A. D. (1986). Working memory. Oxford: Clarendon Press. Baddeley, A. D., Grant, W., Wight, E., \& Thomson, N. (1975). Imagery and visual working memory. In P. M. A. Rabbitt \& S. Dornic (Eds.), Attention and performance $V$ (pp. 205-217). London: Academic Press.

Ballard, P. B. (1913). Oblivescence and reminiscence. British Journal of Psychology (Monograph Supplements), 1(2), 1-82.

BEKERIAN, D. A. (1986). Similarity of internal learning environments and retroactive inhibition. American Journal of Psychology, 99, 45-55.

BELMORE, S. M. (1981). Imagery and semantic elaboration in hypermnesia for words. Joumal of Experimental Psychology: Human Leaming \& Memory, 7, 191-203.

BoWER, G. H. (1970). Imagery as relational organizer in associative learning. Journal of Verbal Learning \& Verbal Behavior, 9, 529-533.

Buxton, C. E. (1943). The status of research in reminiscence. Psychological Bulletin, 40, 313-340.

ERDELYI, M. H. (1984). The recovery of unconscious (inaccessible) memories: Laboratory studies of hypermnesia. In G. H. Bower (Ed.), The psychology of leaming and motivation (Vol. 18, pp. 95-127). New York: Academic Press.

ERdelyi, M. H., \& Becker, J. (1974). Hypermnesia for pictures: Incremental memory for picnures but not words in multiple recall trials. Cognitive Psychology, 6, 159-171.

Erdely, M., Finkelstein, S., Herrell, N., Miller, B., \& Thomas, J. (1976). Coding modality versus input modality in hypermnesia: Is a rose a rose a rose? Cognition, $4,311-319$.
Morton, J., Hammersley, R. H., Bekerian, D. A. (1985). Headed records: A model for memory and its failures. Cognition, 20, 1-23.

Norman, D., Bobrow, D. (1979). Descriptions: A basis for memory acquisition and retrieval. Cognitive Psychology, 11, 107-123.

Paivio, A. V., Yuille, J. C., \& Madigan, S. A. (1968). Concreteness, imagery and meaning values for 925 nouns. Journal of Experimental Psychology Monographs, 76(1, Pt. 2).

PAYNE, D. G. (1986). Hypermnesia for pictures and words: Testing the recall level hypothesis. Joumal of Experimental Psychology: Leaming, Memory, \& Cognition, 12, 16-29.

PAYNE, D. G. (1987). Hypermnesia and reminiscence in recall: A historical and empirical review. Psychological Bulletin, 101, 5-27.

RoEdiger, H. L., PAYNE, D. G. (1982). The role of repeated testing. Joumal of Experimental Psychology: Leaming, Memory, \& Cognition, 8, 66-72.

ROEDIGER, H. L., \& ThORPE, L. A. (1978). The role of recall time in producing hypermnesia. Memory \& Cognition, 6, 196-205.

SHAw, G. A. (1986). Creativity and hypermnesia in high-IQ children. In D. G. Russell, D. F. Marks, \& J. T. C. Richardson (Eds.), Imagery 2: Proceedings of the Second Intemational Imagery Conference. Dunedin, New Zealand: Human Performance Associates.

SHAw, G. A. (1987). Creativity and hypermnesia for words and pictures. Journal of General Psychology, 114, 167-171.

Shaw, G. A., \& BeKerian, D. A. (1989, June). Hypermnesia, laterality and imagery. Paper presented to the Fourth Meeting of the International Society for the Study of Individual Differences, Heidelberg.

THORNDIKE, E., \& LORGE, I. (1944). The teacher's wordbook of 30,000 words. New York: Teacher's College Bureau of Publications.

\section{NOTES}

1. Because of the interactive task, pairs of words were required to be shown during the intertest interval. To prevent subjects from easily discriminating TBR items from interpolated materials on the basis of single words versus pairs, pairs of words were also used during initial encoding.

2. Pilot work showed that all subjects could form interactive images in this time.

(Manuscript received November 4, 1988; revision accepted for publication June 29,1990 .) 